\title{
THE COMPARISON OF THE EFFICIENCY OF SMALL WIND TURBINE GENERATORS WITH HORIZONTAL AND VERTICAL AXIS UNDER LOW WIND CONDITIONS
}

\author{
D. Bezrukovs ${ }^{1}$, V. Bezrukovs ${ }^{1 *}, \mathrm{Vl}$. Bezrukovs ${ }^{1}$, \\ M. Konuhova' ${ }^{1}$ S. Aniskevich² \\ ${ }^{1}$ Engineering Research Institute \\ "Ventspils International Radio Astronomy Centre", \\ Ventspils University of Applied Sciences, \\ 101 Inzenieru Str., Ventspils, LV-3601, LATVIA \\ 2Latvian Environment, Geology and Meteorology Centre \\ 165 Maskavas Str., Riga, LV-1019, LATVIA \\ *e-mail: elmag@inbox.Iv
}

The authors perform a comparative analysis of the efficiency of two types of low-power wind energy conversion systems with horizontal and vertical axis in the meteorological conditions of Latvia. The analysis is based on long-term wind speed measurements over the period of two years conducted by a network of 22 observation stations at the height of $10 \mathrm{~m}$ above the ground. The study shows that in the conditions of Latvia wind turbines with a horizontal axis are expected to work with greater efficiency than similar installations with a vertical axis. The paper presents the models of the spatial distribution of average wind speed, Weibull wind speed frequency distribution parameters and the values of the expected operational efficiency for small wind turbine generators. The modelling results are presented in the form of colour contour maps. Overall, the results of the study can serve as a tool for forecasting annual energy production and for estimating the feasibility of commercial use of wind energy at the height of $10 m$ in the territory of Latvia.

Keywords: Annual Energy Production, map, Small Wind Turbine Generator, wind energy, wind speed at the height of $10 \mathrm{~m}$. 
Due to the lack of significant reserves of fossil fuels in Latvia, the national economy considerably relies on energy import. The dependence of the country's economy on external supplies leads to the fact that the state is interested in supporting power stations using locally available natural resources and renewable energy sources [1]-[6].

Wind currents reaching the Latvian territory from the direction of the Baltic Sea represent a source of renewable energy, which can be used to produce electricity on an industrial scale. Therefore, studies aimed at estimating the expected efficiency of wind energy conversion systems (WECS) depending on their location in the territory of the country are highly relevant.

There is a number of publications devoted to the evaluation of the potential and the distribution of the wind energy resource in the territory of Latvia [7], [8]. However, modern meteorological equipment performing physical wind speed measurements simultaneously in different regions of the country provides a more reliable basis for estimating average wind speed and the spatial distribution of wind energy potential over the land surface.

The authors of the current study perform an assessment of the expected efficiency of low-power wind generators in the wind conditions typical of Latvia. A distinctive feature of these generators is that they transform the energy that wind carries at an altitude of 10-20 $\mathrm{m}$ above the ground surface. In most cases, a Small Wind Turbine Generator (SWTG) is used to power an autonomous load or serve as a backup power source at rural installations, the operation of which does not entirely depend on the power grid connection. Forecast- ing the efficiency of work and determining the Annual Energy Production (AEP) of the SWTG can be done only on the basis of long-term measurements of wind speed. However, the need to perform these measurements and calculate the AEP creates a problem for small households. Therefore, the authors of this study propose to use historical records of long-term measurements of wind speeds that are available in the archive of the national meteorological observation service for forecasting the efficiency of low-power wind generators.

The study is based on wind speed measurements over the period of two years from 1 January 2015 to 31 December 2016 [9]. All wind speed measurements were performed with $1 \mathrm{~min}$ increments at the height of $10 \mathrm{~m}$ above the ground using certified measuring sensors installed at 22 stations of the National Hydrometeorological and Climatological Service of the Latvian Environment, Geology and Meteorology Center (LEGMC).

Based on the available wind speed measurements, data specific indicators of wind energy that characterise the wind flow in this region are derived and an estimation of the average (AEP) for potential wind power plants is performed [10], [11].

The study of the SWTG performance is based on the power curves of two types of SWTG: Horizontal Axis Wind Turbines (HAWT) with rated power of $0.75,2.5,5.0$, $20.0 \mathrm{~kW}$ and Vertical Axis Wind Turbines (VAWT) with $0.75,2.5,6.0 \mathrm{~kW}$.

Based on the results of wind speed measurements and the estimation of the SWTG performance in the territory of Latvia, the models of the spatial distribution of averaged wind speed and wind energy density in the form of colour contour maps with a $1 \times 1$ 
$\mathrm{km}$ resolution were created. The contour maps identify the areas beyond which the measured values change with a certain step.

The developed models of the spatial distribution of the value of capacity factor characterising the effectiveness of the SWTG can serve as a convenient tool and reference material for analysing the feasibility of the SWTG application in various regions of Latvia. The obtained results allow estimating the prospects of commercial use of wind energy at the height of $10 \mathrm{~m}$.
The rest of the paper is structured as follows: Section 2 provides the model of the spatial distribution of wind energy resource in Latvia. Section 3 presents the power curves of the selected SWTG. Section 4 is devoted to spatial distribution modelling of the efficiency of SWTG in Latvia. Section 5 provides the summary of the results, discusses their implications and makes conclusions on the prospects of estimating the SWTG efficiency at the height of $10 \mathrm{~m}$ above the ground.

\section{THE SPATIAL DISTRIBUTION OF WIND ENERGY RESOURCE}

Due to the cyclical nature of wind flows and nonlinear relationship between wind speed and energy it carries, wind energy potential assessment that takes into consideration only average wind speed values can be misleading.

The estimation of the average wind speed value for the period of measurements from 1 January 2015 to 31 December 2016 at each measurement site is performed in line with Eq. 1:

$$
V_{\text {avg }}=\frac{1}{n} \sum_{i=1}^{n} V_{i}
$$

where $V_{i}$ - average wind speed with $1 \mathrm{~min}$ increments, $m / s ; n$ - the number of measurements for the entire period; $i$ - the number of a measurement interval 1, 2, 3 $\ldots n$.

The value of the average energy density that the air flow carries over an area of $1 \mathrm{~m}^{2}$ is calculated from Eq. 2 [12]:

$$
P_{a v g}=\frac{1}{2} \rho V_{a v g . c u b}^{3}
$$

where $\rho$ - air density $\left(1.23 \mathrm{~kg} / \mathrm{m}^{3}\right.$ for standard condition at the sea level and temperature $\left.15^{\circ} \mathrm{C}\right) ; V_{\text {avg.cub }}^{3}$ - average cubic wind speed, $\mathrm{m} / \mathrm{s}$.

Average cubic wind speed can be calculated based on actual wind speed measurements according to Eq. 3:

$$
V_{\text {avg.cub }}=\sqrt[3]{\frac{1}{n} \sum_{i=1}^{n} V_{i}^{3}}
$$

where $V_{i}$ - average wind speed for $1 \mathrm{~min}$ measurement interval, $\mathrm{m} / \mathrm{s} ; n$ - the number of measurements for the entire measurement period; $i$ - the number of a measurement interval $1,2,3 \ldots \mathrm{n}$.

As can be inferred from Eq. (2), the amount of energy carried by the wind is proportional to the value of the average cubic wind speed (see Eq. 3). At the same time, the classification of the territory of Latvia into five categories according to the level of the average cubic wind speed makes it is possible to estimate the potential of the wind energy resource available in these regions. 
Assuming that the maximum value of the average energy density, which the wind carries on the shore of the Baltic Sea, is taken as 1.0 , then the values of the average energy density in relative units for each station will be determined by Eq. 4:

$$
P_{\text {avg.i }}^{\prime}=V_{\text {avg.cub.i }}^{3} / V_{\text {avg.cub.max }}^{3},
$$

where $V_{\text {avg.cub.max }}^{3}$ - average cubic wind speed at Ventspils station situated on the shore of the Baltic Sea; $V_{\text {avg.cub.i }}^{3}$ - average cubic velocity at each of the 22 stations; $i$ - observation station $1,2,3 \ldots 22$.

By interpolating the obtained values, it is possible to create a map of the spatial distribution of the average density of wind energy $P_{a v g . i}^{\prime}$ in the territory of Latvia in relative units, which is shown in Fig. 1.

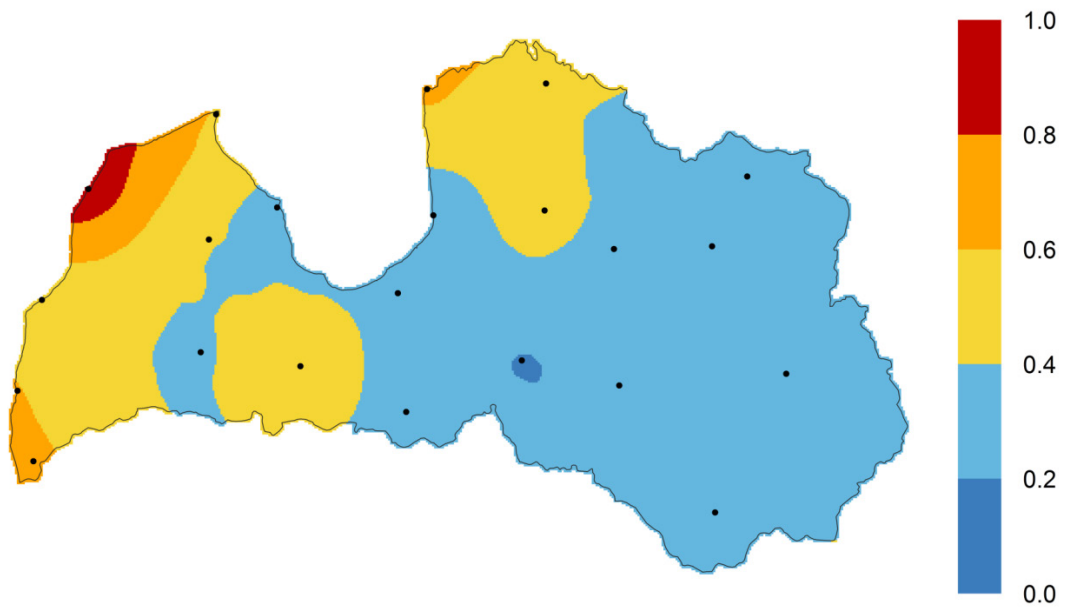

Fig. 1. Model of the spatial distribution of the average wind energy density in relative units $P^{\prime}$ avg at the height of $10 \mathrm{~m}$ above the ground in the territory of Latvia.

Based on the model of the spatial distribution of the average wind energy density in Fig. 1, it is possible to identify regions, where SWTG with mast height of 10-20 m would have the highest efficiency.

\section{POWER CURVE OF SWTG}

Based on the results of wind speed analysis, it is possible to make a forecast with respect to the SWTG performance in the territory of Latvia. The current study considers two types of WECS: HWAT with rated power of $0.75,2.5,5.0,20.0 \mathrm{~kW}$ and VAWT with $0.75,2.5,6.0 \mathrm{~kW}$, which can operate at the height of $10 \mathrm{~m}$. The two types of generators are shown in Figs. 2 and 3, respectively. 


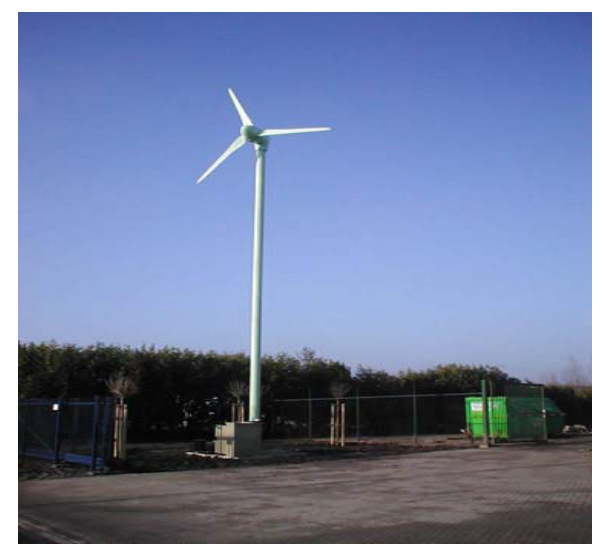

Fig. 2. Horizontal Axis Wind Turbine (HAWT) $0.75 \mathrm{~kW}$.

The main technical and design characteristics of the SWTG are summarised in Table 1. The provided information is in line

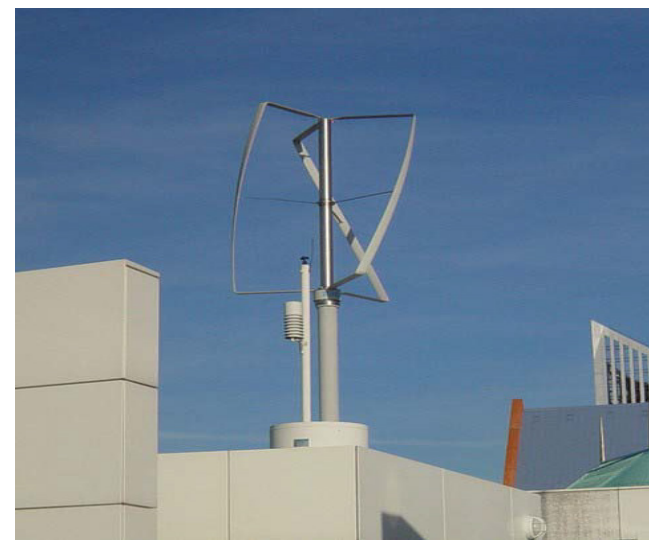

Fig. 3. Vertical Axis Wind Turbine (VAWT) Darrieus H-type $0.75 \mathrm{~kW}$.

with the models presented in the Catalogue of the European Urban Wind Turbine Manufacturers [13].

Table 1. Technical Characteristics of HAWT and VAWT Darrieus

H-Type SWTG with Rated Power of 0.75, 2.5, 5.0, 20.0 $\mathrm{kW}$ and 0.75, 2.5, 6.0 $\mathrm{kW}$

\begin{tabular}{|l|c|c|c|c|}
\hline \multirow{2}{*}{$\begin{array}{l}\text { Turbine } \\
\text { type }\end{array}$} & $\begin{array}{c}\text { Rated power, } \\
\boldsymbol{k} \boldsymbol{W}\end{array}$ & $\begin{array}{c}\text { Rotor height, } \\
\boldsymbol{m}\end{array}$ & $\begin{array}{c}\text { Rotor diameter, } \\
\boldsymbol{m}\end{array}$ & $\begin{array}{c}\text { Rated wind speed, } \\
\boldsymbol{m} / \boldsymbol{s}\end{array}$ \\
\hline \multirow{3}{*}{ VAWT } & 0.75 & 1.50 & 1.50 & 14.0 \\
\cline { 2 - 4 } & 2.50 & 2.88 & 1.99 & 14.0 \\
\cline { 2 - 4 } & 6.0 & 5.00 & 3.30 & 14.0 \\
\cline { 2 - 4 } & 0.75 & & 2.40 & 12.0 \\
\cline { 2 - 4 } & 2.50 & & 5.00 & 11.0 \\
\cline { 2 - 5 } & 5.0 & & 5.40 & 11.0 \\
\cline { 2 - 5 } & 20.0 & & 8.00 & 12.5 \\
\hline
\end{tabular}

The efficiency of a WECS depends on the aerodynamic properties of the wind turbine and the wind type prevailing in the region. Therefore, it is of interest to evaluate the advantages of using both convector types in the specific conditions of the Latvian landscape. For comparison, Fig. 4 shows the power curves of HAWT 0.75 , $2.5 \mathrm{~kW}$ and VAWT 0.75, $2.5 \mathrm{~kW}$.

From the analysis of the power curves, it follows that a distinctive feature of HAWT generators is a steep power curve leading to a higher starting torque. At the same time, as it can be seen from Table 1 and Fig. 4, the rated wind speed for VAWT type generators reaches $14 \mathrm{~m} / \mathrm{s}$, while for HAWT the rated speed is $11-12.5 \mathrm{~m} / \mathrm{s}$. It means that the operating range of the considered VAWT type generators is between 3 and 14 $\mathrm{m} / \mathrm{s}$ while for HAWT type generators it is between 2 and $11-12.5 \mathrm{~m} / \mathrm{s}$. 

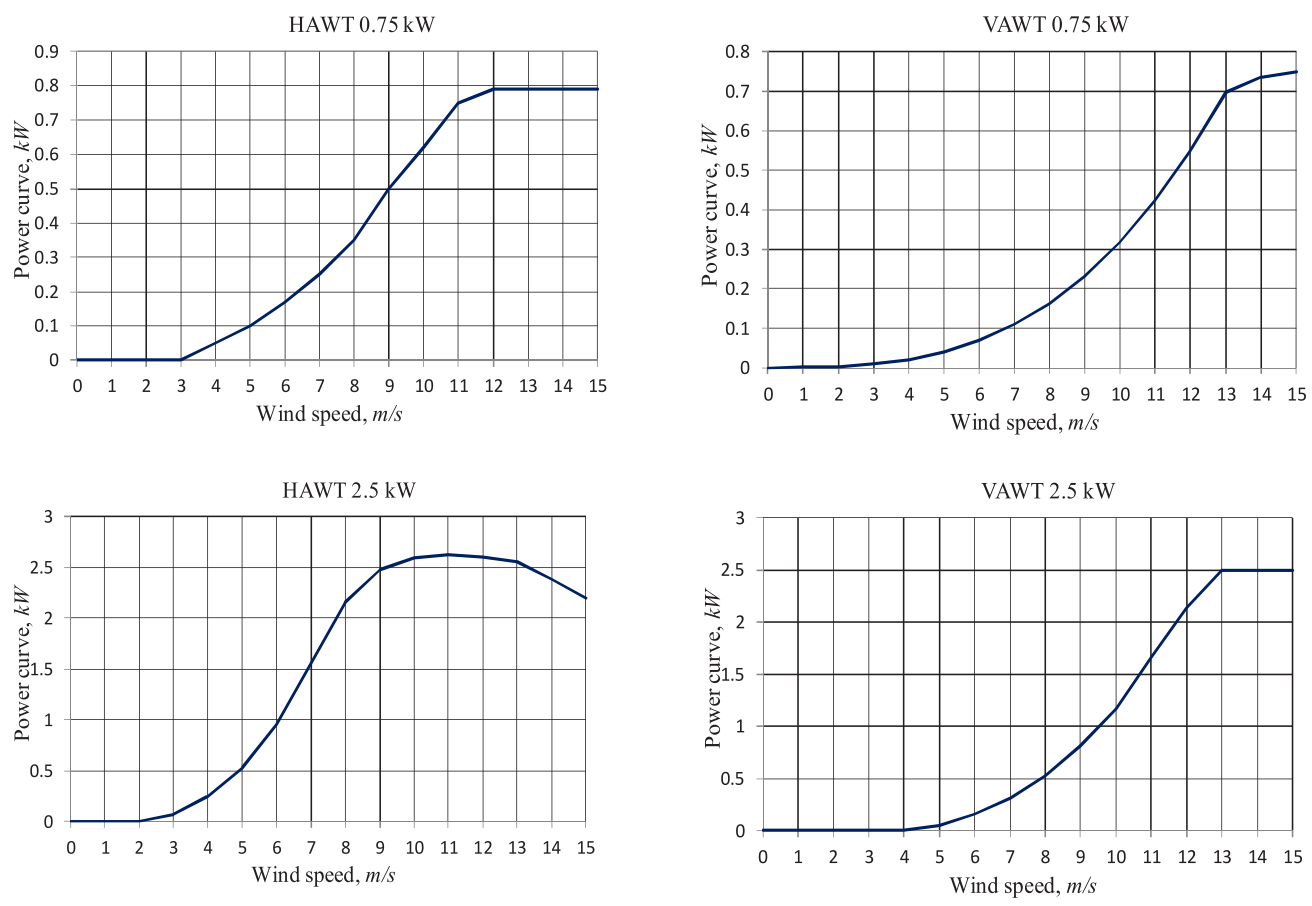

Fig. 4. Power curves $\mathrm{P}(\mathrm{V})$ of HAWT 0.75, $2.5 \mathrm{~kW}$ and VAWT 0.75, $2.5 \mathrm{~kW}$ Darrieus H-type.

\section{MODELLING THE EFFICIENCY OF SWTG}

The nature of the wind is characterised by cyclic changes in the flow speed and the duration of its gusts. On top of it, in various regions, wind fluctuations have characteristic features that are determined by the landscape and geographic proximity to the sea.

The study of wind properties is typically based on the analysis of wind speed measurement results obtained over a long period of time [14]. Methodological approach foresees grouping the measurement results into bins, which correspond to the selected speed intervals with a certain step. For each bin, the total recurrence time of this rate is determined, which can be expressed as a percentage of the total measurement time.

For the analysis of wind speed distribution, the most often used approximation is Weibull probability density function. This function is considered to be a good approximation of the wind speed frequency distribution and is described as follows:

$$
F(V)=\frac{k}{c}\left(\frac{V}{c}\right)^{k-1} \exp \left[-\left(\frac{V}{c}\right)^{k}\right] \quad \text { for } V>0
$$

where $c$-scale factor; $k$ - shape factor; $V$ - wind speed, $m / s$. 
Parameters of the Weibull wind speed frequency distribution functions were estimated using the Maximum Likelihood Method for 22 stations [15]. The maximum likelihood estimator is found by maximising the likelihood function and was calculated using functions from the package MASS of R language [16].

Once the distribution parameters are estimated, it is necessary to perform a goodness of fit test, which checks the conformity between observations and theoretical distribution. This is done by applying the Kolmogorov-Smirnov test, which measures the maximum distance between the empirical and the fitted distribution functions.

The hypothesis that the two distributions are equal is rejected if the distance exceeds a certain critical value [15]. Following the estimation of the parameters of the fitted distribution, it is necessary to assess critical values by applying the bootstrap procedure [17]. Hypothesis was not rejected for any of the stations at $5 \%$ sig- nificance level, thus confirming the applicability of the Weibull distribution for the average wind speed data.

The way, how properties of the wind flow differ across various regions of the country can be represented in the form of a spatial distribution map of Weibull distribution function parameters, as shown in Figs. 5 and 6. The Weibull distribution parameter values depend on regional topography and site proximity to the Baltic Sea and the Gulf of Riga.

The scale parameter values $c$ (Fig. 5), which stretch or shrink the distribution, are decreasing with the distance from the sea, indicating that coastal stations have wider probability density functions. The spatial distribution of the shape parameter values $k$ (Fig. 6) is influenced by topography as the lowest values are observed in the highlands. Overall, the shape parameter $k$ values vary from 1.6 to 2.1 , indicating that the density function has a positively skewed bell shape.

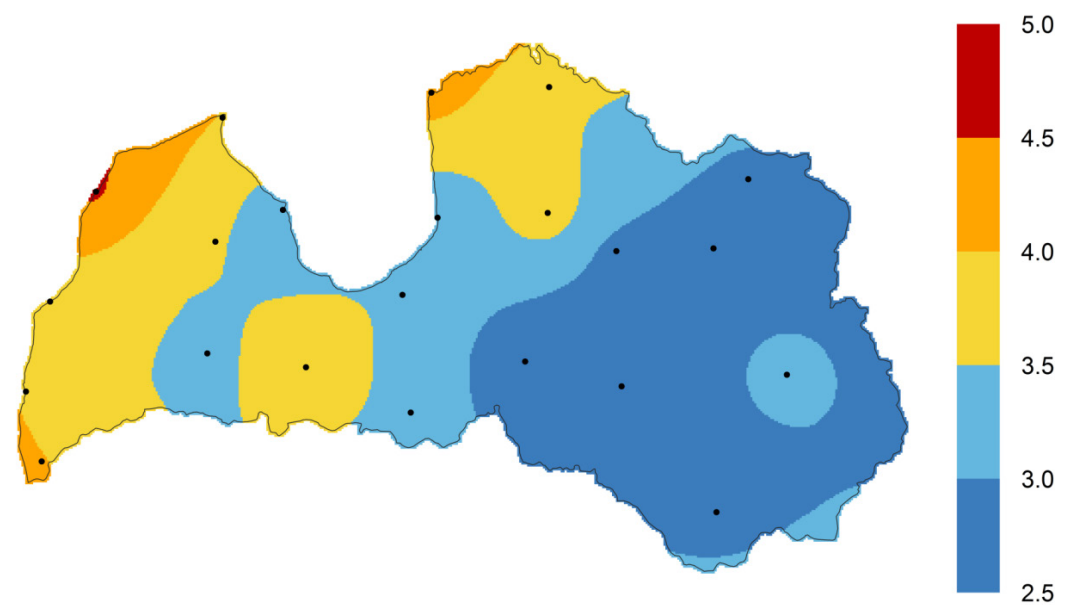

Fig. 5. Model of the spatial distribution values of the scale parameter $c$ of Weibull wind speed probability density at the height of $10 \mathrm{~m}$ above the ground. 


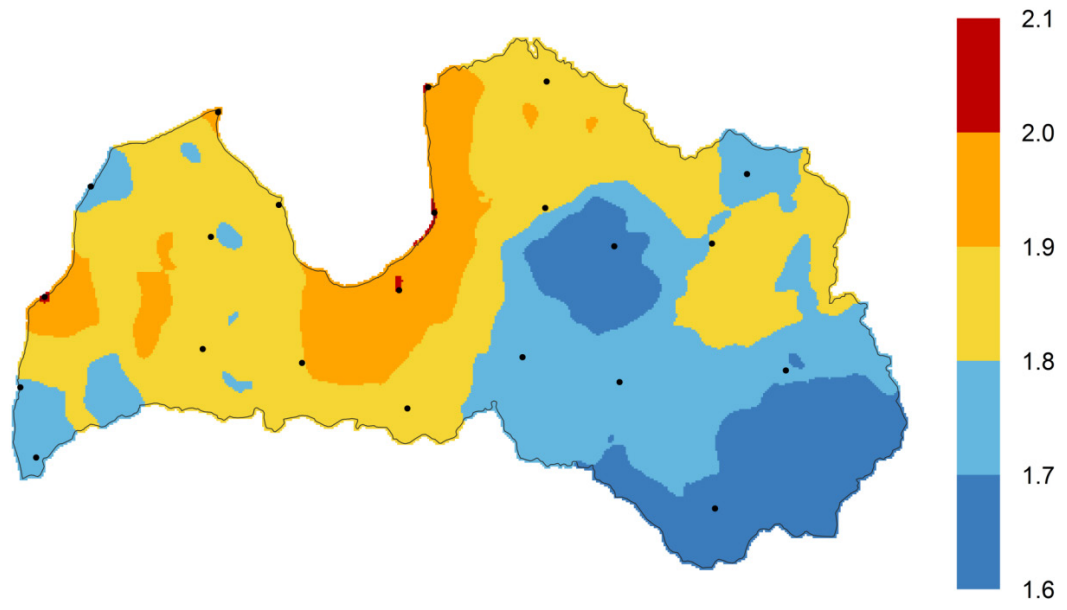

Fig. 6. Model of the spatial distribution values of the shape parameter $k$ of Weibull wind speed probability density at the height of $10 \mathrm{~m}$ above the ground.

The parameters $c$ and $k$ presented in the form of contour maps allow estimating the frequency characteristics of the wind speed distribution for any point in the territory of Latvia at an altitude of $10 \mathrm{~m}$ above the ground using Eq. 5. This greatly simplifies the assessment of the amount of wind energy that can be produced when choosing the location for the SWTG installation.
The values obtained using Eq. (1), (2), (4) and the values of the parameters of the Weibull wind speed frequency distribution function calculated on the basis of measurements at the meteorological observation station in Ainazi, Daugavpils, Priekuli, Saldus and Ventspils for the measurement period from 1 January 2015 to 31 December 2016 are given in Table 2 .

Table 2. The Values of Parameters $c$ and $k$ of the Weibull Wind Speed Frequency Distribution Function, Average Wind Speed $V_{\text {avg }}, V_{\text {avg.cub }}$ and Wind Energy Density in Relative Units $P_{\text {avg.i }}^{\prime}$ for the Selected Meteorological Observation Stations

\begin{tabular}{|l|c|c|c|c|c|}
\hline \multirow{2}{*}{ Stations } & \multicolumn{5}{|c|}{ Measurement results } \\
\cline { 2 - 6 } & $c$ & $k$ & $V_{\text {avg }}$ & $V_{\text {avg.cub }}$ & $P_{\text {avg. } i}^{\prime}$ \\
\hline Ainazi & 4.3 & 2.0 & 3.8 & 4.7 & 0.66 \\
\hline Daugavpils & 2.8 & 1.6 & 2.5 & 3.3 & 0.23 \\
\hline Priekuli & 3.9 & 1.8 & 3.4 & 4.5 & 0.58 \\
\hline Saldus & 3.4 & 1.8 & 3.0 & 3.9 & 0.38 \\
\hline Ventspils & 4.6 & 1.7 & 4.1 & 5.4 & 1.00 \\
\hline
\end{tabular}

The amount of power produced by a wind power converter in a certain period is determined as follows:

$W(V)=\sum_{i=1}^{n}\left(P\left(V_{i}\right) \cdot F\left(V_{i}\right)\right)$,

where $\left(V_{i}\right)$ - generator power curve value for wind speed $V_{i} ; F\left(V_{i}\right)$ - Weibull fre- quency distribution function value for wind speeds $V_{i}$.

Weibull wind speed frequency distribution function $F(V)$, corresponding to the wind type observed in Ventspils region, is presented in Fig. 7 along with the power curve $\mathrm{P}(\mathrm{V})$ for $H A W T 2.5 \mathrm{~kW}$. In Fig. 7 
the area, represented by Eq. 6, corresponds to the AEP of HAWT $2.5 \mathrm{~kW}$ in Ventspils region equal to $W=4.6 \mathrm{MWh}$. Functions $P(V)$ and $F(V)$ were used in the form of discrete bins with $1.0 \mathrm{~m} / \mathrm{s}$ step length. Wind speed for the $i$-th step is determined as follows:

$V_{i}=\Delta V \cdot i$

where $\Delta V-$ bin size $1 \mathrm{~m} / \mathrm{s} ; i-1,2 \ldots n$.
The efficiency of WECS is characterised by the capacity factor $C_{e}$, which is defined as a ratio of the estimated value of $W$ to the potential value of the energy produced by the generator $W_{r}$, assuming that it operates at the rated capacity during the entire period under consideration. Thus, in order to calculate the value of the capacity factor, the following expression is used:

$C_{e}=\frac{W}{W_{r}} \cdot 100(\%)$.

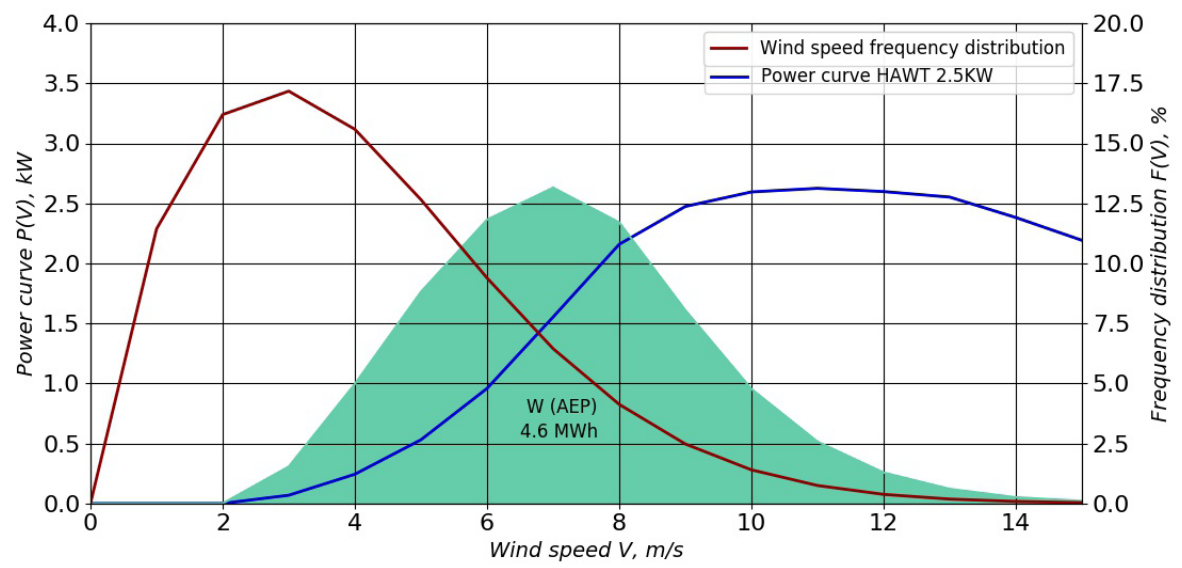

Fig. 7. Wind speed frequency distribution function $\mathrm{F}(\mathrm{V})$, the power curve $\mathrm{P}(\mathrm{V})$ for HAWT $2.5 \mathrm{~kW}$ and the value of AEP W $=4.6 \mathrm{MWh}$, corresponding to wind type at Ventspils meteorological observation station.

The results of the SWTG operational efficiency forecasts depending on the type of wind turbine, rated generator power and the location of its installation for the selected meteorological observation stations (Ainazi, Daugavpils, Priekuli, Saldus and Ventspils) are summarised in Table 3.

Table 3. Capacity Factor $C_{e}$, for HAWT and VAWT Type of the SWTG with Rated Power of 0.75, 2.5, 5.0, $20.0 \mathrm{~kW}$ and $0.75,2.5,6.0 \mathrm{~kW}$ at the Selected Meteorological Observation Stations

\begin{tabular}{|l|c|c|c|c|c|c|c|}
\hline \multirow{2}{*}{ Stations } & \multicolumn{9}{|c|}{ Capacity factor $C_{\boldsymbol{e}} \%$} \\
\cline { 2 - 9 } & \multicolumn{9}{|c|}{ HAWT } & \multicolumn{4}{c|}{ VAWT } \\
\cline { 2 - 9 } & $\mathbf{0 . 7 5} \boldsymbol{k W}$ & $\mathbf{2 . 5} \boldsymbol{k W}$ & $\mathbf{5 . 0} \mathbf{k W}$ & $\mathbf{2 0 . 0} \boldsymbol{k W}$ & $\mathbf{0 . 7 5} \boldsymbol{k W}$ & $\mathbf{2 . 5} \boldsymbol{k W}$ & $\mathbf{6 . 0} \boldsymbol{k W}$ \\
\hline Ainazi & 9.89 & 16.77 & 11.27 & 5.94 & 4.56 & 3.07 & 3.41 \\
\hline Daugavpils & 3.08 & 5,53 & 3.84 & 1.87 & 1.60 & 0.67 & 1.10 \\
\hline Priekuli & 8.06 & 13.67 & 9.25 & 4.88 & 3.79 & 2,49 & 2.82 \\
\hline Saldus & 5.08 & 8.91 & 6.11 & 3.02 & 2.46 & 1.24 & 1.76 \\
\hline Ventspils & 13.33 & 21.24 & 14.56 & 8.49 & 6.45 & 5.24 & 4.96 \\
\hline
\end{tabular}


The summary of the estimates of capacity factor $C_{e}$ for generators of HAWT and VAWT type in Ventspils region are presented in Fig. 8. The comparison shows that regardless of the type, the efficiency of the wind turbine operation decreases with the increasing its rated power. The results of the study suggest that the generators of HAWT type, at the height of at least $10 \mathrm{~m}$ above the ground, are more suitable for operating in wind conditions of Latvia compared to VAWT type generators. Moreover, it is expected that among the wind energy converters of HAWT type considered in the study, generator with the rated power of $2.5 \mathrm{~kW}$ will tend to operate with the highest efficiency.

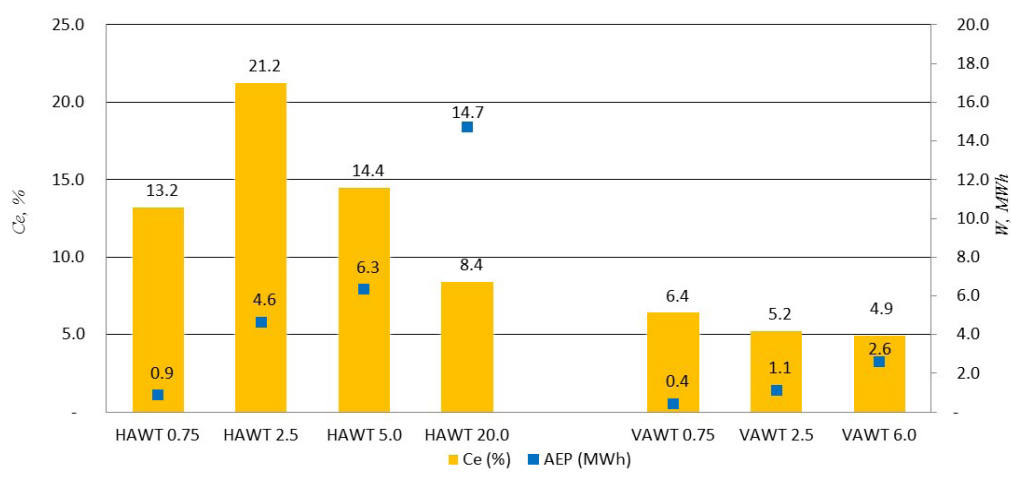

Fig. 8. Forecasted values of capacity factor $C_{e}$ and AEP for HAWT generators with rated power of $0.75,2.5,5.0,20.0 \mathrm{~kW}$ and VAWT Darrieus H-type 0.75, 2.5, 6.0 $\mathrm{kW}$ for Ventspils site.

The efficiency of WECS in the territory of Latvia can be represented as a model of the spatial distribution of the capacity factor $C_{e}$ in relative units. Taking the maximum value of the capacity factor $C_{e \max }$ to serve as the basis, the relative capacity factor $C_{e}{ }_{e}$ for each meteorological observation station can be determined from Eq. 9:

$$
C_{e i}^{\prime}=C_{e i} / C_{e \max },
$$

where $C_{e \max }-$ value of the capacity factor corresponding to the performance of HAWT $2.5 \mathrm{~kW}$ wind power converter for the type of wind observed at Ventspils station; $C_{e i}-$ value of the capacity factor corresponding to the efficiency of the HAWT $2.5 \mathrm{~kW}$ type generator for the wind type at each of the 22 stations.
In this case, the maximum value of the capacity factor corresponds to the SWTG of HAWT type with rated power of $2.5 \mathrm{~kW}$, technical characteristics of which are summarised in Table 1, operating in the meteorological conditions observed at Ventspils observation station.

The developed model of the spatial distribution of factor in relative units is presented in the form of a color contour map in Fig. 9. The figure identifies areas within which HAWT $2.5 \mathrm{~kW}$ is expected to work with the certain level of efficiency relative to the one projected for Ventspils region. Thus, the results of the presented study can serve as a tool for estimating and forecasting the feasibility of the commercial use of small wind turbine generators at the altitude of $10 \mathrm{~m}$ in the territory of Latvia. 


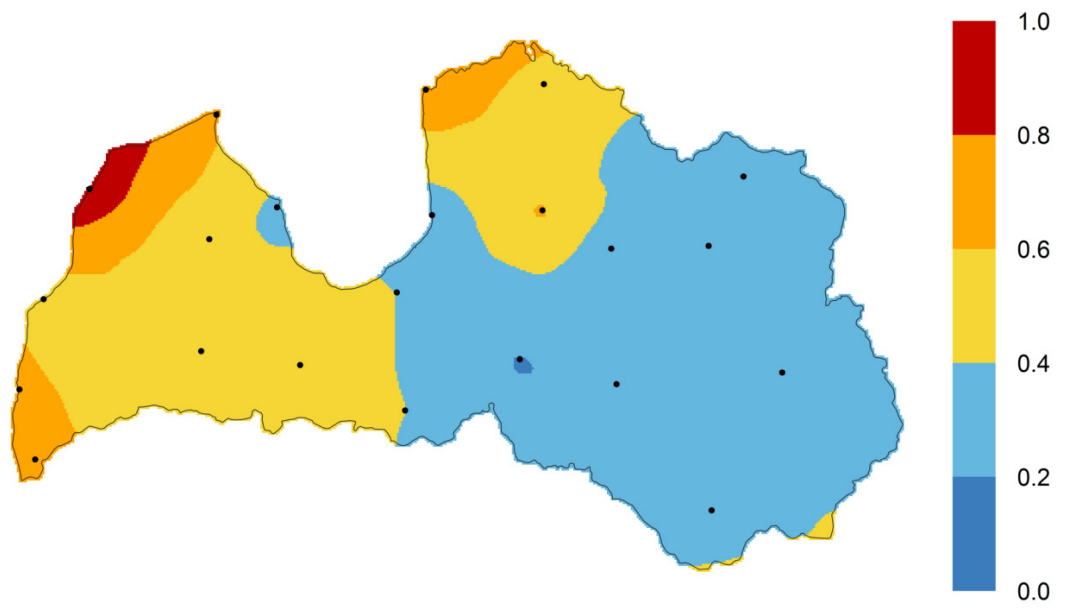

Fig. 9. Model of the spatial distribution of the relative capacity factor for HAWT type generator with rated power of $2.5 \mathrm{~kW}$ at the height of $10 \mathrm{~m}$ above the ground.

\section{CONCLUSIONS}

The national network of 22 meteorological stations in Latvia provides a unique opportunity for compiling the map of the spatial distribution of wind energy potential in the country at the height of $10 \mathrm{~m}$ above the ground.

The study presented the spatial distribution models of average wind speed, parameters of Weibull wind speed distribution, relative wind energy density and operational efficiency of the SWTG at the height of $10 \mathrm{~m}$ above the ground. The spatial models were presented in the form of colour contour maps.

The study provided the comparative analysis of two SWTG types: HAWT type with rated power of $0.75,2.5,5.0,20.0 \mathrm{~kW}$ and VAWT Darrieus H-type with rated power of $0.75,2.5,6.0 \mathrm{~kW}$. The results of the comparison suggest that HAWT type generators with rated power of $2.5 \mathrm{~kW}$ would tend to perform better than other WECS under consideration in terms of efficiency in Latvian meteorological conditions.

The results of the study can serve as a tool for forecasting AEP and estimating the feasibility of the commercial use of wind energy at the height of $10 \mathrm{~m}$ in the territory of Latvia.

\section{ACKNOWLEDGEMENTS}

The research has been carried out within the projects of the Ministry of Economics of the Republic of Latvia "Innovative Smart Grid Technologies and Their Optimization (INGRIDO)", project No. VPP-EM-
INFRA-2018/1-0006 and "Future-Proof Development of the Latvian Power System in an Integrated Europe (FutureProof)", project No. VPP-EM-INFRA-2018/1-0005. 


\section{REFERENCES}

1. Bezrukovs, D., \& Sauhats, A. (2017). Economic and Operational Risks in Wind Energy Projects in Latvia. Renewable Energy and Power Quality Journal, 15, 1-6. ISSN 2172-038X.: DOI:10.24084/ repqj15.326.

2. Sauhats, A., Zemīte, L., Petričenko, L,., Moškins, I., \& Jasevičs, A. (2018). Estimating the Economic Impacts of Net Metering Schemes for Residential PV Systems with Profiling of Power Demand, Generation, and Market Prices. Energies, 11 (11), 1-19. DOI: 10.3390/en11113222.

3. Petrichenko, L., Broka, Z., Sauhats, A., \& Bezrukovs, D. (2018). Cost-benefit analysis of Li-Ion batteries in a distribution network. In Proceedings of the 2018 15th International Conference on the European Energy Market (EEM), 27-29 June 2018 (pp. 1-5). Łódź, Poland.

4. Zemite, L., Petrichenko, L., Sauhats, A., Linkevics, O., \& Bockarjova, G. (2018). A Comparative Assessment of the SmallScale Distributed Generation Policies in the EU and Latvia. In Solar \& Wind Integration Workshop: E-Mobility Integration Symposium, 1/2018, (pp. 1-6).

5. Shipkovs, P., Kashkarova, G., Lebedeva, K., $\&$ Migla, L. (2012). Use of renewable energy resources for reduction of environmental pollutions. The Fourth IASTED African Conference on Power and Energy Systems (AfricaPES 2012), (79-85), 3-5 September 2012, Gaborone, Botswana. CD Proceedings, ISBN: 978-0-88986-929-5.

6. Bobinaite, V., \& Priedite, I. (2015). RES-E Support Policies in the Baltic States: Electricity Price Aspect (Part II). Latvian Journal of Physics and Technical Sciences, $2,13-25$.

7. Ostapenko, J., \& Gamalejevs, A. (2004). Latvian wind energy guide. Riga, 96 p. Available at http://www.windenergy.lv/ startpage/lv/

8. Bezrukovs, V., Zacepins, A., Bezrukovs, V., \& Komashilovs, V. (2016). Investigations of Wind Shear Distribution on the Baltic
Shore of Latvia. Latvian Journal of Physics and Technical Sciences, 53 (3), 3-10.

9. Aniskevich, S., Bezrukovs, V., Zandovskis, U., \& Bezrukovs, D. (2017). Modelling the spatial distribution of wind energy resources in Latvia. Latvian Journal of Physics and Technical Sciences, 54 (6), 10-20. DOI: 10.1515/lpts-2017-0037.

10. Bezrukovs, V., Bezrukovs, Vl., \& Zacepins, A. (2014). Comparative Efficiency of Wind Turbines with Different Heights of Rotor Hubs: Performance Evaluation for Latvia. J. Phys.: Conf. Ser. 524012113. DOI:10.1088/1742-6596/524/1/012113.

11. Godoy Simões, M., \& Farret, F.A. (2014). Modelling and analysis with induction generators (3rd ed.). CRC Press.

12. Manwell, J. F., McGowan, J. G., \& Rogers, A. L. (2009). Wind energy explained: Theory, design and application. USA: John Wiley \& Sons Ltd.

13. Catalogue of European Urban Wind Turbine Manufacturers. (2017). Available at http:// www.urbanwind.net/pdf/CATALOGUE V2.pdf

14. Bezrukovs, V., Zacepins, A., Bezrukovs, Vl., \& Komashilovs, V. (2016). Comparison of Methods for Evaluation of Wind Turbine Power Production by the Results of Wind Shear Measurements on the Baltic Shore of Latvia. Renewable Energy, 96, Part A, 765-774.

15. Storch, H. von, \& Zwiers, F.W. (2003). Statistical analysis in climate research. Cambridge: Cambridge University Press.

16. Ripley, B., Venables, B., Bates, D.M., Hornik, K., Gebhardt, A., Firth, D. (2017). Support Functions and Datasets for Venables and Ripley's MASS. Available at https://cran.r-project.org/web/packages/ MASS/

17. Kharin, V.V., \& Zwiers, F.W. (2000). Changes in the Extremes in an Ensemble of Transient Climate Simulations with a Coupled Atmosphere-Ocean GCM. Journal of Climate, 13, 3760-3788. 